Derecho comercial 


\title{
Algunas consideraciones sobre la distribución de dividendos en las sociedades anónimas
}

\author{
Ricardo de la Piedra Calle
}

\section{Introducción}

Cuando Michael Douglas - representando a Gordon Gekko en la famosa película Wall Street (por la que ganó un Óscar de la Academia en 1988) - se dirige a los accionistas de la empresa Teldar Paper y señala que "la avaricia, a falta de una mejor palabra, es buena", 1 no estaba del todo errado. Las personas y corporaciones que invierten en negocios, siempre lo hacen buscando un rédito a cambio. Así, la familia que constituye una sociedad familiar para dedicarse al negocio de venta de pasteles de la mamá o de joyería artesanal de la hija mayor, lo hace para obtener una ganancia de dicho negocio, tanto o igual como la transnacional japonesa que adquiere una planta en Perú a cientos de millones de dólares, lo hace con el fin de obtener utilidades y ganancias para sus accionistas o inversionistas. En el mundo empresarial, uno de los aspectos fundamentales - sino el principal- es que el negocio genere utilidades y se reditúe la inversión.

Ahora bien, ¿realmente conocen los accionistas de una sociedad anónima cuáles son los alcances del famoso derecho a "participar en las

1 La frase original de Michael Douglas es: “The point is, ladies and gentlemen, that greed, for lack of a better word, is good [...]". 
utilidades de la sociedad"? La sociedad familiar que reparte dividendos a diestra y siniestra, cada mes, para las vacaciones de los hijos, el pago de gastos familiares y el alquiler de la casa de playa, ¿cumple con las políticas establecidas por nuestra normativa para el reparto de dividendos a cuenta y los destinos obligatorios previos a la distribución?

El objetivo del presente artículo es detallar de manera general las disposiciones de la Ley General de Sociedades peruana (en adelante, LGS) respecto a la distribución de dividendos, describiendo los destinos obligatorios que deben tener las utilidades obtenidas por la sociedad en determinado ejercicio, e incluyendo una explicación sobre la muy utilizada figura de los dividendos a cuenta.

\section{El derecho a participar en las utilidades. Conceptos preliminares}

Como hemos señalado en la introducción, los accionistas, al constituir o adquirir una sociedad, tienen como objetivo principal obtener resultados positivos con la marcha societaria, a efectos de generar beneficios que puedan ser repartidos entre ellos. Sobre esta base, pasamos a detallar los conceptos preliminares que deben tenerse en cuenta sobre el derecho a participar en las utilidades.

\subsection{El derecho al dividendo en sí}

El de participar en las utilidades es un derecho fundamental para los accionistas de una sociedad. Tanto es así, que el artículo 95 de la LGS, ${ }^{2}$ referido a las acciones comunes con derecho a voto, señala con claridad, en su inciso primero, que dicha clase de acción confiere a su titular, en adición a la calidad de accionista, al menos el derecho a participar en el reparto de utilidades. La misma lógica se mantiene para las acciones sin derecho a voto en el artículo $96,{ }^{3}$ con la adición del artículo

2 Artículo 95.- Acciones con derecho a voto

La acción con derecho a voto confiere a su titular la calidad de accionista y le atribuye, cuando menos, los siguientes derechos:

1. Participar en el reparto de utilidades [...].

3 Artículo 96.- Acciones sin derecho a voto

La acción sin derecho a voto confiere a su titular la calidad de accionista y le atribuye, cuando menos, los siguientes derechos: 
$97^{4}$ de la misma norma, respecto a que las acciones sin derecho a voto dan a sus titulares el derecho a percibir el dividendo preferencial que establezca el estatuto; es decir, en este último caso se compensa la carencia del derecho a voto con un dividendo preferencial. Esta es una regla imperativa e inderogable por el estatuto social.

Como podemos observar, independientemente del tipo de acción de la que se es titular, los accionistas cuentan con un derecho fundamental a participar en las utilidades de la sociedad. Elías (2011: 192) sostiene que de no cumplirse el derecho patrimonial del accionista a las utilidades, la finalidad elemental y característica de este no podría cumplirse. Además, el derecho a participar en las utilidades le permite al accionista procurarse los beneficios económicos obtenidos por el desarrollo de las actividades que constituyen el objeto social.

\subsection{Los estados financieros}

Aceptado que los accionistas de una sociedad anónima cuentan con el derecho a participar en las utilidades de esta, ¿cómo podemos saber a ciencia cierta a cuánto ascienden esas utilidades? La respuesta a esta pregunta la encontramos en los estados financieros de la sociedad, los que según la cuarta disposición final de la LGS son el balance general y el estado de ganancias y pérdidas, que muestran los resultados económicos de su actividad.

Los estados financieros, según dispone la LGS, deberán ser preparados y presentados de conformidad con las disposiciones legales sobre la materia y con principios de contabilidad generalmente aceptados en el Perú, a efectos de que de esos documentos resulte con claridad y precisión la situación económica y financiera de la sociedad, el estado de sus negocios y los resultados obtenidos en el ejercicio vencido, siendo dichas características muy importantes para que los accionistas tomen

Participar en el reparto de utilidades [...] con la preferencia que se indica en el artículo 97;

$[\ldots]$.

4 Artículo 97.- Preferencia de las acciones sin derecho a voto

Las acciones sin derecho a voto dan a sus titulares el derecho a percibir el dividendo preferencial que establezca el estatuto.

Existiendo utilidades distribuibles, la sociedad está obligada al reparto del dividendo preferencial a que se refiere el párrafo anterior.

$[\ldots]$. 
una decisión sobre la aplicación de utilidades, en el caso de que las hubiere.

\subsection{Principios que guían la distribución de utilidades}

Más allá de los requisitos formales - de los que trataremos más adelante-, concordamos plenamente con Hundskopf (2006: 59) cuando resalta dos principios fundamentales recogidos en nuestra legislación respecto a la distribución de dividendos:

a) Principio de proporcionalidad o prorrateo: Recogido en el artículo 39 de la LGS, y que dispone que la distribución de beneficios a los socios se realiza en proporción a sus aportes al capital, esto es, en base a su participación accionaria en la sociedad. La misma LGS permite que vía pacto en contrario en el estatuto se puedan fijar proporciones o formas distintas de distribución de beneficios.

b) Principio de universalidad: Regulado también en el artículo 39 de la LGS, dispone expresa y categóricamente la prohibición de que el pacto social excluya a determinados socios de las utilidades, o los exonere de toda responsabilidad por las pérdidas, salvo por los socios que aportan únicamente servicios en este último caso.

La regla, como se observa, es que los socios participen en las utilidades en la misma proporción en que participan en el capital social. Los pactos distintos pueden incorporarse no solo en el estatuto, sino también en un pacto de accionistas (sobre este último punto no ahondaremos, por no ser materia del presente trabajo ${ }^{5}$ ).

\subsection{El derecho a las utilidades y el derecho al dividendo}

Ahora bien, antes de proseguir con la finalidad de este artículo, es importante dejar en claro la diferencia entre el derecho a las utilidades y el derecho al dividendo propiamente dicho. Para tales efectos nos remitimos a la explicación de Hernández Gazzo (2003: 108), quien diferencia con mucha claridad entre el derecho abstracto a las utilidades que tienen todos los accionistas de una sociedad, por su sola calidad de

5 Para mayor referencia en relación con las limitaciones de los convenios entre accionistas y accionistas y terceros, el mencionado tema ha sido desarrollado por el autor en De la Piedra (2010). 
tales, y el derecho materializado a cobrar dividendos, que es, a fin de cuentas, un derecho de crédito plenamente efectivo y ejercitable frente a la sociedad. ${ }^{6}$

El mismo criterio utiliza Uría (1982: 215-216) cuando establece la distinción entre el derecho a participar en las ganancias como derecho corporativo inconcreto y abstracto, y el derecho al dividendo repartible en un determinado ejercicio económico.

Así, lo que debe quedar claro es que en virtud del derecho a las utilidades se tiene un derecho potencial, abstracto, no materializado, a participar en una eventual distribución de dividendos que acuerde la sociedad con base en sus estados financieros a determinado periodo. El derecho al dividendo se materializa una vez que la junta de accionistas acuerda distribuir dividendos; es en ese momento que el accionista adquiere la calidad de acreedor de la sociedad y surge la obligación de pago, de parte de esta, frente al accionista. Citando a Hernández Gazzo (2003: 109), el dividendo es, entonces, la utilidad que se distribuye o va a distribuirse.

Por otro lado, lo que sucede contablemente una vez acordada la distribución de dividendos es lo siguiente: se carga la cuenta patrimonial de resultados acumulados (en el monto correspondiente al acuerdo), disminuyéndola en el monto por repartir; y se abona dicho monto en una cuenta por pagar a los accionistas en el pasivo de los estados financieros de la sociedad. Esta cuenta del pasivo es la que precisamente refleja la deuda de la sociedad y su nueva condición de deudora frente a los accionistas, quienes a su vez adquieren la calidad de acreedores en dicho acto.

\section{Destinos obligatorios y optativos para la aplicación de las utilidades}

Al formular los estados financieros correspondientes a un periodo y verificar que ellos arrojan utilidades, se debe tener en cuenta que la LGS establece algunos destinos obligatorios para estas y deja a disposición

6 Agrega Hérnandez Gazzo que "este derecho abstracto, conocido en doctrina como 'derecho abstracto a las utilidades', es, en esencia, el derecho potencial que todo accionista tiene a participar en las utilidades de la sociedad. Ese derecho potencial sólo será materializado si, entre otras condiciones, se cumple una fundamental, a saber: que la sociedad arroje utilidades [...]". 
del directorio de la sociedad o la junta de accionistas otras opciones. Así, tenemos:

\subsection{Destinos obligatorios}

Están, dentro de los destinos obligatorios o imperativos por mandato de la LGS u otras normas:

a) La compensación obligatoria de pérdidas acumuladas. Destino regulado en el segundo párrafo del artículo 40 de la LGS, según el cual, si se ha perdido una parte del capital, no se pueden distribuir utilidades hasta que este sea reintegrado o reducido en la cantidad correspondiente. El caso contemplado es el de una sociedad que tiene pérdidas acumuladas y obtiene utilidades en el ejercicio siguiente. Como señala Elías (2011: 91), en este supuesto la sociedad está obligada a compensar primero sus pérdidas acumuladas, con cargo a las utilidades obtenidas, y solo así podrá después distribuir el saldo - de haberlo - entre los accionistas.

b) Tributos. Desde el punto de vista tributario, antes de proceder a la distribución de dividendos se deberá determinar la renta correspondiente y pagar los demás tributos inherentes.

c) Beneficios de los socios fundadores. Según lo dispuesto en el artículo 72 de la LGS, independientemente de su calidad de accionistas, los socios fundadores de una sociedad pueden reservarse derechos especiales de diverso contenido económico, los que deben constar en el estatuto. Siendo esto así, el estatuto de una sociedad podría contemplar la aplicación obligatoria de cierta parte de las utilidades en beneficios para los socios fundadores, consistentes en una participación en las utilidades. Cabe señalar que, según el mismo artículo, esos beneficios no podrán exceder en conjunto la décima parte de la utilidad distribuible anual que arrojen los estados financieros de los primeros cinco años, en un periodo máximo de diez años contados a partir del ejercicio siguiente de la constitución de la sociedad.

d) Retribución del directorio. Este destino será aplicable, evidentemente, solo si se trata de sociedades anónimas que cuentan con directorio; hecha la salvedad, recuérdese que de conformidad con el artículo 166 de la LGS, el cargo de director es siempre retribuido. La LGS vigente - a diferencia de la anterior- permite a los directores participar en las utilidades de la sociedad, sin perjuicio de la 
retribución que se les asigne (Elías 2011: 348-349); así, dicha ley establece que si se ha acordado la participación de los directores en las utilidades de la empresa, ella solo podrá ser detraída de las utilidades líquidas y, en su caso, después de la detracción de la reserva legal correspondiente al ejercicio (de la cual tratamos en el literal siguiente).

e) Reserva legal. El artículo 229 de la LGS dispone la obligación de que un mínimo del $10 \%$ de la utilidad distribuible de cada ejercicio, deducido el impuesto a la renta, se destine a la reserva legal, hasta que esta alcance un monto igual a la quinta parte del capital (20\%). Al respecto, concordamos con Hundskopf (2006: 59) cuando señala que la existencia de dicha reserva constituye una especie de escudo o barrera de protección para el futuro. Por su parte, Elías (2011: 504) sostiene que las reservas le proporcionan a una empresa mayor solidez económica y financiera.

Empero, si bien la LGS dispone que el exceso sobre el límite del 20\% del capital no constituye reserva legal y, en principio, una vez alcanzado ese porcentaje no habría obligación de aportar montos a reservas de la sociedad, podría existir lo que se denomina reservas estatutarias. Según esta figura, cabe que el estatuto de la sociedad disponga que determinado porcentaje de las utilidades se destinen a una reserva para un fin específico, con lo cual se puede tener cubierta la reserva legal al máximo exigido por ley, y por dicha disposición subsistirá la obligación imperativa de destinar determinada porción de las utilidades a reservas.

\subsection{Destinos optativos}

Cumplidos los destinos imperativos, entre las principales opciones voluntarias para aplicar las utilidades (además de ser las más comunes en la marcha societaria de las empresas) están:

a) Aplicar las utilidades del ejercicio a las utilidades acumuladas. Esto no merece mayor comentario, pues el título se explica por sí solo.

b) Capitalizar la utilidad. Mediante un aumento del capital social se emitirán nuevas acciones o aumentará el valor nominal de las existentes, según lo estipulado en el inciso 3 del artículo 202 de la LGS.

c) Distribución de las utilidades. Esto se hace, como se ha dicho, materializando el derecho mediante la distribución de dividendos en una cuenta por cobrar a favor del accionista frente a la sociedad. 
Evidentemente, estas opciones no son excluyentes entre sí. La junta de accionistas podrá destinar parte de las utilidades a una capitalización y distribuir un monto determinado, según convenga a los intereses de la sociedad y de los propios accionistas. La decisión sobre el destino de las utilidades dependerá de la situación de cada sociedad y del análisis que efectúen administradores y accionistas.

\section{Requisitos para la distribución de utilidades y algunos aspectos que se deben considerar}

Descritos los aspectos principales que deben tenerse en cuenta para la distribución de utilidades, corresponde detallar los requisitos que la LGS establece para el reparto de utilidades como dividendos en una sociedad anónima:

1. La distribución de utilidades solo puede hacerse en mérito de los estados financieros preparados al cierre de un determinado periodo. Según el artículo 221 de la LGS, corresponde al directorio, una vez finalizado el ejercicio económico, formular la memoria, los estados financieros y, en caso de haber utilidades, formular una propuesta de aplicación de estas, la que será aprobada o desaprobada por la junta general, atendiendo a la situación financiera de la sociedad y de los accionistas.

La junta obligatoria anual de accionistas debe pronunciarse necesariamente sobre la aplicación de las utilidades respecto a los estados financieros aprobados en dicha junta. Esta obligación se encuentra contemplada en forma expresa en el artículo $114^{7}$ de la LGS, el cual señala que la distribución se hace con base en los estados financieros al cierre de un ejercicio o de un determinado periodo, en las circunstancias especiales que acuerde el directorio. Así pues, cuando la repartición de dividendos se da en este últi-

7 Artículo 114.- Junta obligatoria anual

La junta general se reúne obligatoriamente cuando menos una vez al año dentro de los tres meses siguientes a la terminación del ejercicio económico. Tiene por objeto:

[...]

Resolver sobre la aplicación de las utilidades, si las hubiere;

$[\ldots]$. 
mo caso, nos encontramos ante el supuesto de repartición de dividendos a cuenta (el cual comentaremos más adelante).

Cabe indicar que en las sociedades que no cuenten con directorio, estas obligaciones recaen en el gerente general.

2. Las sumas que se repartan no pueden exceder del monto de las utilidades que efectivamente se hayan obtenido. Por simple que pueda parecer este requisito, es fundamental en tanto apunta a proteger el patrimonio de la sociedad y, por ende, el interés de sus acreedores, accionistas y terceros contratantes. Concordamos con Hernández Gazzo (2003: 111) cuando afirma que distribuir utilidades inexistentes a los accionistas supone la entrega o devolución de activos de una forma encubierta, obviando el procedimiento formal para la reducción de capital que prevé la LGS, lo cual implica, entre otras cosas, omitir publicaciones y la consiguiente posibilidad de que acreedores y terceros legitimados ejerzan el derecho de oposición. Elías (2011: 91) sostiene una posición similar sobre el particular.

3. Solo pueden ser pagados dividendos en razón de utilidades obtenidas o de reservas de libre disposición, y siempre que el patrimonio neto no sea inferior al capital pagado. Este requisito se encuentra recogido en el artículo 230 de la LGS. Concordamos con Hernández Gazzo (2003: 114) cuando sostiene que no es adecuado que este artículo requiera que la comparación del patrimonio neto se efectúe con el capital pagado y no con el capital suscrito, dado que el capital pagado es, en el mejor de los casos, igual al capital suscrito. Así, tenemos dos supuestos: i) si todo el capital suscrito está pagado, la precisión es inocua; y ii) si el capital suscrito no está totalmente pagado, el hecho de establecer una comparación entre patrimonio neto y capital pagado (en lugar del suscrito) flexibilizaría este requisito, tomando en cuenta que el capital pagado sería inferior. Podría darse el caso de que pese a que el patrimonio neto sea inferior al capital suscrito, y siendo mayor al capital pagado, la utilidad pueda, efectivamente, ser repartida.

4. Todas las acciones de la sociedad, aun cuando no se encuentren totalmente pagadas, tienen el mismo derecho al dividendo. Según Hundskpof (2006: 64-65), el fin de esta norma es corregir un artículo de la ley anterior, mediante el cual se establecía que los dividendos debían distribuirse necesariamente en proporción a las sumas 
desembolsadas, dispositivo que por su complejidad y ambigüedad generaba situaciones injustas entre los accionistas de una sociedad. Así pues, con esta norma se establece que mientras los accionistas no sean morosos, gozan de iguales derechos en relación con la repartición de dividendos, sin importar el porcentaje pagado de cada una de sus acciones. ${ }^{8}$ En el mismo sentido se pronuncia Elías (2011: 513-514).

5. La junta de accionistas debe determinar el momento y forma de pago del dividendo. Lo usual es que en la misma junta que apruebe la distribución de dividendos se establezcan los términos y condiciones para el cobro o, en su defecto, se encargue a la administración de la sociedad materializar lo dispuesto por la junta. Como señala Hundskpof (2006: 65-66), una vez acordada la distribución de dividendos puede ser que el pago del dividendo acordado se haga inmediatamente o que la junta, en función de la liquidez de la sociedad, programe un calendario de pagos parciales.

6. Los accionistas preferenciales y los accionistas sin derecho a voto. Es importante tener en cuenta que, al lado de los accionistas titulares de acciones con derecho a voto, pueden existir accionistas preferenciales o accionistas sin derecho a voto dentro de la sociedad. El artículo 88 de la LGS permite que en una sociedad anónima puedan coexistir diversas clases de acciones. Así, es perfectamente posible que existan (como en la práctica ocurre) acciones que cuenten con derechos preferenciales en la repartición de dividendos sobre las utilidades distribuibles.

En adición a lo expuesto, hemos mencionado que el artículo 97 de la LGS dispone que las acciones sin derecho a voto otorgan a su titular el derecho a percibir el dividendo preferencial que establezca el estatuto. Siendo así, la situación particular de este tipo de acciones también debe ser considerada en la oportunidad de repartir los dividendos.

7. Es obligatoria la repartición de dividendos cuando lo soliciten accionistas que representen al menos el $20 \%$ de las acciones suscritas con derecho a voto. Consideremos que el artículo 231 de la LGS establece la obligatoriedad de la distribución de dividendos en dinero hasta

8 El cual, como se sabe, según lo dispuesto por el artículo 84 la LGS, no puede ser en ningún caso inferior al $25 \%$. 
por un monto igual a la mitad de la utilidad distribuible de cada ejercicio, luego de detraído el monto que debe aplicarse a la reserva legal, si así lo solicitan accionistas que representen cuando menos el $20 \%$ del total de las acciones suscritas con derecho a voto.

Este artículo defiende el derecho de las minorías accionarias a obtener un dividendo. Como indica Elías (2011: 516), en las sociedades anónimas se producen con frecuencia conflictos entre el interés de los accionistas a obtener un dividendo y el de la administración por reforzar el patrimonio neto de la sociedad o por reinvertir las utilidades en nuevos proyectos. Incluso los grupos mayoritarios de accionistas pueden preferir la reinversión de las utilidades en el negocio de la sociedad durante largos periodos, en perjuicio de los accionistas minoritarios, quienes no se verán beneficiados con la repartición de dividendos.

Así pues, mediante esta disposición se protege en alguna forma el derecho de las minorías a obtener un dividendo después de finalizado el ejercicio - en la medida en que existan utilidades - y a la vez se previene que los grupos mayoritarios puedan verse facultados a privar, en forma indefinida, del dividendo a los accionistas minoritarios.

\section{Caducidad del cobro de dividendos}

Como establece el artículo 232 de la LGS, el derecho a cobrar el dividendo caduca a los tres años, contados desde la fecha en que su pago era exigible conforme al acuerdo de declaración del dividendo. Los dividendos cuya cobranza haya caducado incrementan la reserva legal de la sociedad.

Es importante tener en cuenta lo señalado por Hundskpof (2006: 69), quien hace hincapié en que todos los plazos de la LGS son de caducidad y no de prescripción, por lo que no son susceptibles de suspensión o interrupción, concluyendo y extinguiéndose el derecho con el simple transcurso del tiempo.

En lo que respecta a las sociedades anónimas abiertas, el plazo de caducidad para el cobro de dividendos es de diez años. 


\section{Dividendos repartidos irregularmente}

Como se ha explicado, el artículo 40 de la LGS establece tres principios fundamentales para la distribución de dividendos:

i) No pueden distribuirse utilidades si antes no hay estados financieros que demuestren la existencia de las que serán repartidas.

ii) El monto repartido no puede exceder del monto de las utilidades que haya obtenido la sociedad.

iii) No pueden repartirse utilidades si la sociedad tiene pérdidas acumuladas.

Los dos primeros principios pueden resumirse de una manera simple: "No se pueden distribuir utilidades cuando no las hay; y si las hay, no se puede distribuir mayor cantidad que la que arroja el balance" (2011: 91).

Dada la importancia de estos principios, la LGS dispone sanciones a la distribución irregular de utilidades. Así, el mismo artículo otorga la posibilidad, tanto a la sociedad como a sus acreedores, de poder repetir por cualquier distribución de utilidades hecha en contravención de las normas que dicho artículo contiene, de las siguientes formas:

i) Contra los socios que hayan recibido las utilidades distribuidas irregularmente; o

ii) Exigiendo su reembolso a los administradores que las hubiesen pagado, asumiendo estos últimos una responsabilidad solidaria.9

$\mathrm{Al}$ respecto, la LGS dispone que los socios que hubieran actuado de buena fe estarán obligados solo a compensar las utilidades recibidas con las que les correspondan en los ejercicios siguientes o con la cuota de liquidación que pudiera tocarles.

En las sociedades anónimas que no cuenten con directorio, las responsabilidades por la distribución irregular de utilidades recaen en el gerente general.

9 Según Hundskopf, la responsabilidad de la administración de la sociedad anónima opera exclusivamente en los casos en que se hubiera producido una colusión con los accionistas para falsear los estados financieros y propiciar con ello un reparto indebido de utilidades, enmarcándose dicha responsabilidad dentro del tercer párrafo del artículo 40. 


\section{El caso de los dividendos a cuenta}

\subsection{Regulación}

Los incisos 3, 4 y 5 del artículo 230 de la LGS permiten la distribución de dividendos a cuenta, salvo para las empresas sobre las que recaiga prohibición expresa (es el caso de las empresas del sistema financiero nacional). La posibilidad de repartir esta clase de dividendos fue una novedad de la LGS vigente, respecto a su antecesora.

Debe entenderse como dividendos a cuenta las utilidades que la sociedad acuerda repartir sobre la base de un balance distinto al anual. En ese sentido, lo que se considera para repartir las utilidades es un balance parcial, a una fecha determinada de corte.

\subsection{Requisitos}

Para la repartición de dividendos a cuenta rigen los mismos requisitos que para la repartición de dividendos regular, con las siguientes diferencias:

i) Se necesita un balance general preparado con base en una fecha de corte determinada, previo al cierre del ejercicio económico. Esto es diferente del balance anual que se utiliza para la repartición de dividendos regular, acordada en la junta obligatoria anual de accionistas.

ii) Se requiere la opinión favorable del directorio; en caso contrario, la responsabilidad por el pago recaerá en forma exclusiva sobre los accionistas que votaron a favor del acuerdo.

La razonabilidad de la repartición de los dividendos a cuenta parte del hecho de que, a determinado punto del año, la sociedad puede haber obtenido utilidades que le permitan seguir funcionando correctamente en el marco de sus operaciones y, a la vez, repartir entre los accionistas algo del beneficio que ha obtenido a esa determinada fecha. Como se ha dicho, el fin de quienes invierten en sociedades es obtener un rédito, y sus necesidades no son necesariamente anuales. Tomando esto en consideración, el problema es determinar si la situación ventajosa de la sociedad se mantendrá hasta el cierre del ejercicio, para lo cual hay una serie de variables que analizar. Basta pensar en la crisis mundial del 2009 para darnos cuenta de que solo teniendo una bola de cris- 
tal se podría saber con exactitud cuáles serán los resultados económicos de un ejercicio.

\subsection{Restitución o compensación}

Una interpretación sistemática de los artículos 230 y 40 de la LGS conduce a la conclusión de que los accionistas están obligados a restituir las utilidades que reciban a cuenta o a compensarlas con las que les correspondan por los ejercicios siguientes, en el caso de que las utilidades repartidas a cuenta no se materialicen al final del ejercicio.

\subsection{Delegación en el directorio}

Es válido que la facultad de acordar el reparto de dividendos a cuenta en la sociedad se delegue en el directorio. Este podrá acordar la distribución de un dividendo a cuenta, incluso sin necesidad de una decisión posterior de la junta, asumiendo las responsabilidades inherentes a dicha repartición.

\section{Conclusión}

El tratamiento que otorga la LGS a los dividendos en las sociedades anónimas no es del todo simple, y hay determinados requisitos y obligaciones que la administración y accionistas de la sociedad deben cumplir a fin de evitar incurrir en responsabilidades, más aún si nuestra legislación otorga la posibilidad de repartir dividendos a cuenta y si se considera, además, la volatilidad e imprevisibilidad del mercado económico actual.

Tomando en cuenta la naturaleza eminentemente económica de las inversiones y la constitución de empresas, así como el fin lucrativo que este tipo de actividades persigue, es importante que se tengan presentes los principios y regulaciones mencionados en estas páginas, a los efectos de tener un mayor entendimiento de algunos derechos que otorga la ley al accionista, como el dividendo preferencial de las acciones sin derecho a voto o la distribución obligatoria de dividendos si así lo solicitan accionistas que representen al menos el $20 \%$ del capital social suscrito de la sociedad.

Finalmente, cabe señalar que el abarcamiento de todos los aspectos de la repartición y la aplicación de utilidades no ha sido el objetivo del presente trabajo, pues de serlo hubiera resultado no solo bastante más 
extenso, sino también probablemente muy teórico. Lo que hemos buscado ha sido brindar el marco general de la repartición de dividendos y hacer hincapié en los principales aspectos que deben considerarse al momento de su repartición a fin de no infringir normas fundamentales relacionadas con la aplicación de utilidades.

\section{Bibliografía}

De la Piedra Calle, Ricardo (2010). “iHasta que la muerte los separe? Comentarios a la regulación de los convenios parasocietarios". Diálogo con la Jurisprudencia 144. Lima: Gaceta Jurídica.

Elías Laroza, Enrique (2011). Derecho societario peruano. La Ley General de Sociedades del Perú. Trujillo: Normas Legales.

Hernández Gazzo, Juan Luis (2003). “Consideraciones sobre el reparto de utilidades en las sociedades anónimas". Themis 46. Lima.

Hundskopf Exebio, Oswaldo (2006). “La distribución de dividendos, las entregas a cuenta y los supuestos de restitución a la sociedad anónima". Derecho comercial. Temas societarios. Tomo VI. Lima: Fondo Editorial de la Universidad de Lima.

Uría González, Rodrigo (1982). Derecho mercantil. 12. a edición. Madrid: Imprenta Aguirre. 